\title{
Effects of temperature on the oncospheres of the cestode Microsomacanthus hopkinsi and its implication for their over-winter survival
}

\author{
JOHN LEE \\ Department of Biology, Concordia University, 1455 de Maisonneuve Boulevard W., Montréal, Que., Canada H3G $1 M 8$ \\ Wilfred Pilgrim \\ Department of Biology, University of New Brunswick, Bag Service Number 45111, Fredericton, N.B., Canada E3B 6E1 \\ J. D. McLaughin ${ }^{1}$ \\ Department of Biology, Concordia University, 1455 de Maisonneuve Boulevard W., Montréal, Que., Canada H3G 1M8 \\ AND \\ M. D. B. BuRT \\ Department of Biology, University of New Brunswick, Bag Service Number 45111, Fredericton, N.B., Canada E3B $6 E 1$
}

Received August 9, 1991

Accepted December 24, 1991

Lee, J., Pilgrim, W., Mclaughlin, J. D., and Burt, M. D. B. 1992. Effects of temperature on the oncospheres of the cestode Microsomacanthus hopkinsi and its implication for their over-winter survival. Can. J. Zool. 70: 935-940.

In an attempt to determine whether hymenolepidid oncospheres may overwinter and contribute to the pool of cysticercoids in the intermediate host population the following spring, we studied the survival of the oncospheres of the cestode Microsomacanthus hopkinsi following storage at 7 and $20^{\circ} \mathrm{C}$, following short-term freezing under laboratory conditions, and after overwintering (October-May) under natural conditions at depths of $0.5,1$, and $1.5 \mathrm{~m}$ in a local lake. Viability was tested by feeding the oncospheres to laboratory-reared amphipods (Hyalella azteca). The percentage of surviving amphipods that became infected following exposure to oncospheres stored at $7^{\circ} \mathrm{C}$ declined steadily from $96 \%$ following 4 weeks storage to $43 \%$ after 24 weeks. Only $3 \%$ ( 2 of 60 ) were infected following exposure to oncospheres stored for 28 weeks. Oncospheres held overwinter under natural conditions failed to produce infections. These were slightly older ( 29 weeks) than the oldest oncospheres maintained at $7^{\circ} \mathrm{C}$ in the laboratory, at the time of feeding to the amphipods. It appears that 28 weeks approaches the maximum survival time for the oncospheres of this species. Oncospheres subjected to short-term freezing also failed to produce infections when fed to amphipods. Oncospheres survived in sufficient numbers for up to 24 weeks to be of potential significance in the formation of infective pools in amphipods in the spring. However, there is a northern limit beyond which the inactive period of the amphipod host is too long for the oncospheres to bridge. Under these circumstances, they are of no consequence in the formation of the infective pool. Only 5\% (3 of 60) of the amphipods exposed to oncospheres stored at $20^{\circ} \mathrm{C}$ for 4 weeks became infected. Foci established in warmer conditions, as expected, are infective for much shorter periods.

Lee, J., Pilgrim, W., Mclaughlin, J. D., et Burt, M. D. B. 1992. Effects of temperature on the oncospheres of the cestode Microsomacanthus hopkinsi and its implication for their over-winter survival. Can. J. Zool. 70 : $935-940$.

Nous avons tenté de déterminer si les oncosphères des hyménolépidides peuvent survivre à l'hiver et contribuer au pool de cysticercoïdes chez l'hôte intermédiaire au cours du printemps suivant; dans ce but, nous avons étudié la survie des oncosphères du cestode Microsomacanthus hopkinsi après une période passée à 7 ou à $20^{\circ} \mathrm{C}$, après une courte période de gel dans des conditions de laboratoire, ou après une saison d'hiver (octobre à mai) passée dans des conditions naturelles à des profondeurs de $0,5,1$ ou $1,5 \mathrm{~m}$ dans un lac local. Les oncosphères ont été données en nourriture à des amphipodes élevés en laboratoire (Hyalella azteca) afin d'en tester la viabilité. Le pourcentage d'amphipodes qui sont devenus infectés après exposition à des oncosphères gardées à $7^{\circ} \mathrm{C}$ a diminué progressivement d'un pourcentage de $96 \%$, après 4 semaines de maintien à $7^{\circ} \mathrm{C}$, à un pourcentage de $43 \%$ après 24 semaines. Seulement $3 \%$ ( 2 sur 60$)$ ont été infectés après exposition à des oncosphères gardées pendant 28 semaines. Les oncosphères gardées dans des conditions naturelles pendant l'hiver n'ont causé aucune infection. Il s'agissait d'oncosphères légèrement plus âgées (29 semaines) que les oncosphères les plus vieilles gardées en laboratoire à $7^{\circ} \mathrm{C}$ lorsqu'elles ont été offertes aux amphipodes. Il semble donc que 28 semaines soit près de la durée maximale de survie des oncosphères de cette espèce. Les oncosphères soumises à une courte période de gel sont restées sans effet sur les amphipodes. Les oncosphères ont survécu en nombre suffisamment grand jusqu'à 24 semaines pour assurer la formation de pools infectieux chez les amphipodes au printemps. Cependant, il y a une limite nord au-delà de laquelle la période inactive de l'hôte amphipode est trop longue pour que les oncosphères puissent survivre. Dans ces circonstantes, elles n'ont aucune impact sur la formation de pools infectieux. Seulement $5 \%$ (3 sur 60) des amphipodes exposés à des oncosphères gardées à $20^{\circ} \mathrm{C}$ pour 4 semaines sont devenus infectés. Comme il fallait le prévoir, des foyers d'infection établis dans des conditions plus chaudes sont infectieux pour des périodes beaucoup plus courtes.

[Traduit par la rédaction]

\section{Introduction}

Hymenolepidid cestodes of migratory Holarctic waterfowl undergo seasonal variation in prevalence and intensity (e.g., Tsimbalyuk 1965; Buscher 1965; Kornyushin 1973; McLaughlin and Burt 1973; Wallace and Pence 1986; Birova et al. 1989; Spakulova et al. 1989). Typically, the prevalence and magni-

\footnotetext{
'Author to whom all correspondence should be addressed.
}

tude of infection by most helminth species is highest in summer, declines through the fall, and reaches the lowest levels during winter. Infection levels increase throughout the spring, particularly after arrival on the nesting grounds, to levels seen later in the summer.

The factors that contribute to the increase in infection levels in the spring are poorly studied. Most waterfowl species harbour light to moderate infections of a variety of hymenolepidid 
species during spring migration (Wallace and Pence 1986) and when they arrive on the nesting grounds (Schiller 1954; Buscher 1965; McLaughlin and Burt 1973; 1979; Nerassen and Holmes 1975). Eggs passed from these hosts are the major source of the infective pools established in local invertebrate populations each year (Schiller 1954; Buscher 1965; Nerassen and Holmes 1975). However, existing pools may also await returning waterfowl. The cysticercoids of a number of hymenolepidid species can overwinter in the crustacean intermediate host (e.g., Kotel'nikov 1969; Czaplinski and Szelenbaum 1974; Mineev 1980) or in snail resevoir hosts (Rysavy 1961).

On the other hand, the ability of oncospheres to overwinter and their potential contribution to the infective pool remains virtually unknown. If oncospheres passed during fall migration survive the winter, they could have an important impact on the size and diversity of local cysticercoid populations the following spring. Survival at low temperature varies considerably among the few hymenolepidids studied. Oncospheres of Drepanidotaenia lanceolata, Diorchis stefanskii, and Sobolevicanthus gracilis may survive for up to 25, 80, and 140 days, at $2-5^{\circ} \mathrm{C}$ (Kisilewska 1957; Baginska-Olszewska and GrytnerZiecina 1978; Grytner-Ziecina 1980, respectively), and those of $S$. gracilis show some resistance to short-term freezing, suggesting that this species might survive the winter under natural conditions (Grytner-Ziecina 1980).

Microsomacanthus hopkinsi is a small cestode that occurs in the caeca of dabbling ducks (Anas spp.). Like a number of other small microsomacanthids that occur primarily in scaup, $M$. hopkinsi sheds its oncospheres in packets and utilizes amphipods as the intermediate host (Podesta and Holmes 1970). Hyalella azteca is the only known intermediate host (McLaughlin and Burt 1970; Podesta and Holmes 1970). Hyalella populations survive the winter, but individuals are inactive below $10^{\circ} \mathrm{C}$ (de March 1981). Hence packets deposited after the amphipods become inactive in late fall would remain uneaten until the following spring. If sufficiently long lived, these packets could serve as a source of infection when the amphipods resume activity in spring.

In this study, oncospheres of $M$. hopkinsi were subjected to short-term freezing, overwintering conditions in a local lake, and storage under different temperature regimes. The objectives were twofold; first, to evaluate the ability of the oncospheres to overwinter, and second, to determine the effective duration of foci established in simulated early and late spring conditions as part of the overall life-cycle dynamics of this particular group of hymenolepidid cestodes.

\section{Materials and methods}

The oncospheres of Microsomacanthus hopkinsi are shed in clusters called packets; each packet contains all the oncospheres of a single proglottis. Packets used in the initial study were obtained from black ducks shot near Fredericton, New Brunswick. Packets used for the subsequent experiments were obtained from the caecal droppings of wild mallards that were livetrapped at Delta, Manitoba. These were fed to laboratory-reared amphipods and used to establish infections in ducklings from which material for the experiments was obtained.

Domestic ducklings, purchased from Brome Lake Duck Farms, Knowlton, Quebec, were used as laboratory hosts. These were kept in parasite-free facilities at Concordia University and maintained on a diet of $18 \%$ laying feed (Nutribec Ltd., Montréal). Food and fresh water were available ad libitum. When about 2 weeks old, each duckling received $10-15$ infected amphipods.

Egg packets were collected from the caecal droppings of the ducklings beginning 8 days postexposure. Fresh droppings were dissolved in water and filtered through a $95-\mu \mathrm{m}$ sieve, and the residue was resuspended and examined for packets under low-power magnification.

In the preliminary study, packets were stored in vials in incubators at $5,10,15,20$, and $25^{\circ} \mathrm{C}$. These were fed to laboratory-reared Hyalella azteca at 4-week intervals for 20 weeks. At each interval, groups of $H$. azteca were exposed en masse to several packets that had been stored at each temperature. Amphipods were kept at $20^{\circ} \mathrm{C}$ for 14 days then dissected to evaluate infection success. If infections failed to develop from packets stored for 4 weeks at a particular temperature, a second set of infections was performed as above using oncospheres that were 1,2 , or 3 weeks old.

Subsequently, four experiments were performed. In each, freshly collected egg packets were placed in cylindrical containers $3.5 \mathrm{~cm}$ long $\times 3 \mathrm{~cm}$ in diameter. These were made from Drosophila culture vials cut to the required size. They were screened at each end with squares of 38- $\mu \mathrm{m}$ nylon mesh, held in place by Drosophila vial caps (Carolina Biological Supply Co., Burlington, N.C.), and submerged until required.

\section{Experiment 1: Storage at $7^{\circ} \mathrm{C}$}

Seven hundred packets were collected over a 3-day period and stored at $7{ }^{\circ} \mathrm{C}$. Eight packets were placed in each of 84 numbered containers. Twenty-eight containers were placed in each of three 10 -gallon ( 1 gallon $=4.5 \mathrm{dm}^{3}$ ) aquaria set up in a cold room at $7^{\circ} \mathrm{C}$. The water was aerated constantly and half the volume was replaced on a weekly basis.

At 4-week intervals, four containers were chosen at random from each tank. The packets from the containers from each tank were pooled and 20 packets were selected for use: This provided three groups of 20 packets per interval. The remaining packets were fixed in $5 \%$ formalin. Before being fed to amphipods, the total number of oncospheres in each packet was counted and the number of abnormal oncospheres, if any, noted. To keep a record of the dose given to each amphipod, each packet was fed to an amphipod in a numbered vial. Two days later, each amphipod was transferred to a larger, identically numbered vial containing about $10 \mathrm{~cm}^{3}$ of water and a small tuft of filamentous algae. The amphipods were kept at $20 \pm 2^{\circ} \mathrm{C}$ for an additional 12 days, then examined.

Prior to dissection, the length of the head capsule was measured. Because most amphipods were measured live, reliable body lengths were difficult to obtain. Head capsule length is a good estimator of body size in $H$. azteca (see de March 1978) and this measurement was used in analyses rather than body length. The mean head length of the $H$. azteca used in this study was $0.52 \pm 0.09 \mathrm{~mm}$. Amphipods were dissected in depression slides and the parasites counted under low-power magnification. Amphipods that died were dissected and examined for parasites as soon as they were found, but decomposition occurred rapidly and little information was obtained from these.

Sixty freshly collected packets obtained at the same time as the experimental material were used as controls. The oncospheres were counted and the packets fed to $H$. azteca within $24 \mathrm{~h}$ of collection. Exposure and examination were performed as described above.

\section{Experiment 2: Storage at $20^{\circ} \mathrm{C}$}

This experiment ran concurrently with experiment 1 . The protocol was identical except that the packets were held at $20 \pm 2{ }^{\circ} \mathrm{C}$.

\section{Experiment 3: Overwintering under natural conditions}

Approximately 200 packets collected at the same time as those described above were divided into 12 equal lots and placed in containers as described above. Four containers were placed in each of three nylon screen bags that were placed on the bottom of a local lake at depths of $0.5,1$, or $1.5 \mathrm{~m}$ in October 1989. These were recovered in early May 1990 (29 weeks). Unfortunately, many of the packets had matted together and could not be separated without breaking. Instead, three subsamples of 20 intact packets, each pooled from the containers at a particular depth, were used. The oncospheres were counted and the packets fed to amphipods as described in experiment 1 . 


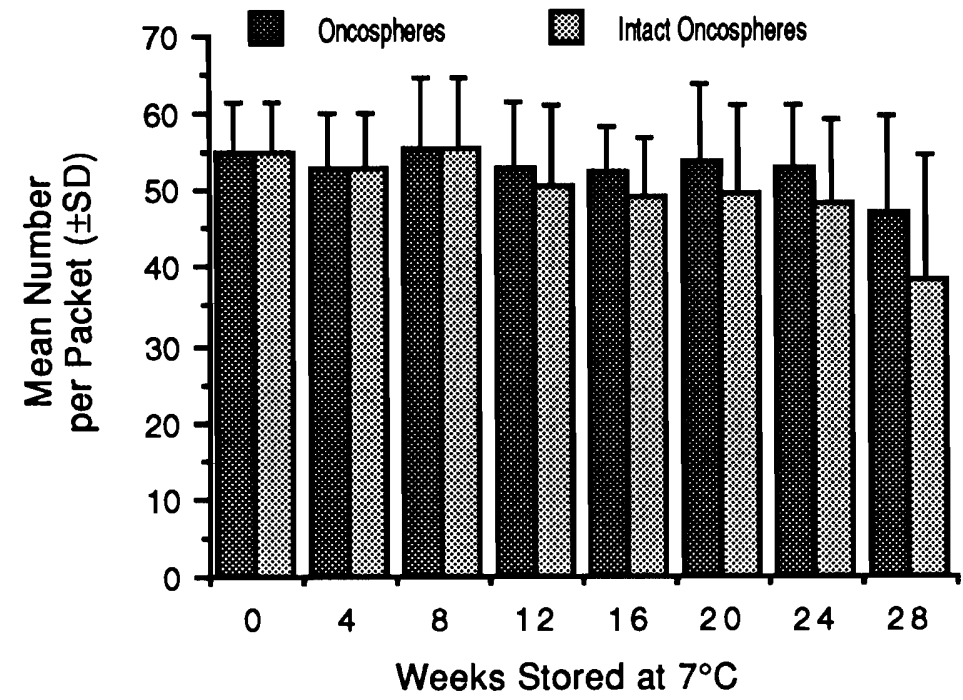

FIG. 1. Microsomacanthus hopkinsi. A comparison of the total mean number of oncospheres and the mean number of intact oncospheres in control packets and in packets stored at $7^{\circ} \mathrm{C}$ for $4,8,12,16,20,24$, and 28 weeks. Vertical bars represent the + ve standard deviation.

\section{Experiment 4: Effects of short-term freezing}

To evaluate the effects of freezing, packets were frozen under laboratory and natural conditions. Separate vials of 1- to 2-day-old packets were placed in a freezer. One was left for $4 \mathrm{~h}$, the other for $12 \mathrm{~h}$. The water in the vial stored for $4 \mathrm{~h}$ was only partially frozen when retrieved; the water in the vial stored for $12 \mathrm{~h}$ was frozen solid. After thawing, the packets were fed en masse to amphipods. In another trial, a container with 16 freshly collected packets was placed in a shallow pan full of culture water and left outdoors for 2 days during which the temperature dropped to $-5^{\circ} \mathrm{C}$. The water in the pan was frozen solid for at least $12 \mathrm{~h}$ during this period. These packets were allowed to thaw slowly and the oncospheres examined, counted, and then fed immediately to amphipods as described in experiment 1 .

\section{Statistical analyses}

Statistical analyses included least-squares regression analysis, analysis of variance, and chi-square. The intensity data were not normally distributed and were transformed prior to analysis. A square-root transformation gave the closest approximation to a normal distribution. All analyses involving intensity were performed using transformed data. Probabilities of $P \leq 0.05$ were considered significant.

\section{Results}

Figure 1 compares the mean total number of oncospheres and the mean number of intact oncospheres in the control packets and in those stored at $7{ }^{\circ} \mathrm{C}$ (experiment 1 ). Regression analysis revealed that the mean total number of oncospheres per packet did not differ significantly between the groups. However, there was a significant decline in the mean number of intact oncospheres $\left(F_{[1,6]}=16.95 ; P<0.01\right)$. From about day 84 , increasing numbers of damaged oncospheres were observed and some had disappeared completely (Figs. 2 and 3). The mean number of oncospheres per packet in the sample stored at $20^{\circ} \mathrm{C}$ (experiment 2 ) was $53.8 \pm 7.4$. An average of $27.3 \pm$ 16 oncospheres per packet (51\%) still appeared normal after 1 month. None of the packets stored for 2 months or longer at $20^{\circ} \mathrm{C}$ had intact oncospheres and no further exposure of amphipods was attempted. The mean numbers of oncospheres and intact oncospheres in the overwintered packets (experiment 3) were $40.8 \pm 5.9$ and $19.9 \pm 13.6,32.6 \pm 9$ and $15.2 \pm 10$, and $40.2 \pm 9.3$ and $19.3 \pm 15.2$ for the subsamples from depths of $0.5,1$, and $1.5 \mathrm{~m}$, respectively. Overall,

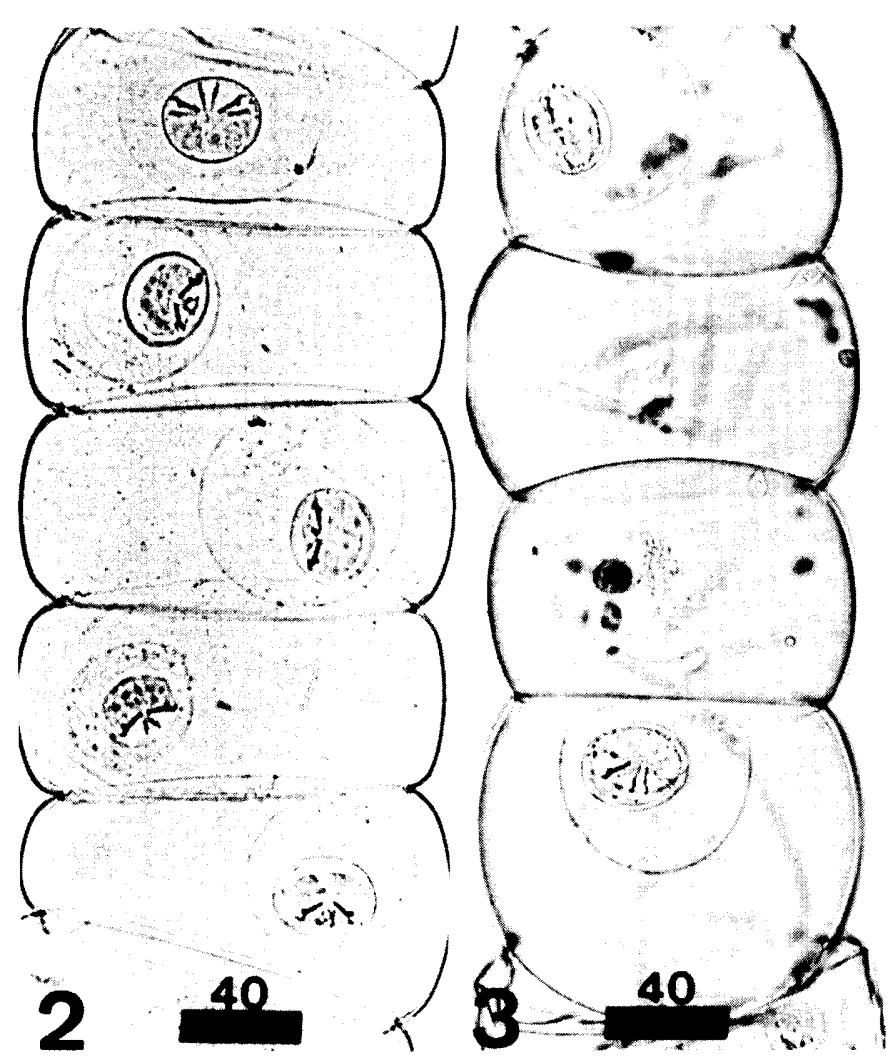

FIGs. 2 and 3. Microsomacanthus hopkinsi packets. Fig. 2. Fresh packet showing intact oncospheres. Fig. 3. Formalin-fixed packet that had been stored for 28 weeks at $7^{\circ} \mathrm{C}$, showing apparently normal (first and fourth) and damaged (second and third) oncospheres. Both packets were photographed at the same magnification.

49,47 , and $48 \%$ of the oncospheres in these samples appeared normal.

The initial study revealed that oncospheres kept at 5 and $10^{\circ} \mathrm{C}$ were infective for up to 20 weeks and those kept at $15^{\circ} \mathrm{C}$ were infective for about 12 weeks, whereas those stored at 20 and $25^{\circ} \mathrm{C}$ were infective for less than 4 weeks. Additional 
TABLE 1. Summary of Microsomacanthus hopkinsi infections in Hyalella azteca following storage of packets at $20^{\circ} \mathrm{C}$ and $7{ }^{\circ} \mathrm{C}$, and following short-term freezing and overwintering under natural conditions at depths of $0.5,1$, and $1.5 \mathrm{~m}$

\begin{tabular}{|c|c|c|c|c|c|c|}
\hline \multirow[b]{2}{*}{ Treatment } & \multirow{2}{*}{$\begin{array}{l}\text { Age of } \\
\text { packets } \\
\text { (weeks) }\end{array}$} & \multicolumn{3}{|c|}{ H. azteca } & \multicolumn{2}{|c|}{ M. hopkinsi } \\
\hline & & $n$ & $\%$ surviving & $\begin{array}{l}\% \text { survivors } \\
\text { infected }\end{array}$ & $\begin{array}{c}\text { Mean } \\
\text { intensity }\end{array}$ & SD \\
\hline \multirow[t]{2}{*}{$20^{\circ} \mathrm{C}$} & 0 & 60 & 73 & 93 & 35.7 & 12.3 \\
\hline & 4 & 60 & 63 & 5 & 2.5 & 2.1 \\
\hline \multirow[t]{8}{*}{$7^{\circ} \mathrm{C}$} & 0 & 60 & 73 & 93 & 35.7 & 12.3 \\
\hline & 4 & 60 & 78 & 96 & 22.3 & 10.1 \\
\hline & 8 & 60 & 83 & 84 & 28.2 & 15.7 \\
\hline & 12 & 60 & 72 & 81 & 18.6 & 14.5 \\
\hline & 16 & 60 & 73 & 71 & 14.9 & 10.8 \\
\hline & 20 & 60 & 95 & 56 & 12.3 & 12.1 \\
\hline & 24 & 60 & 82 & 43 & 5.8 & 5.6 \\
\hline & 28 & 60 & 90 & 4 & 4.0 & 1.4 \\
\hline \multicolumn{7}{|l|}{ Lake } \\
\hline $0.5 \mathrm{~m}$ & 29 & 20 & 60 & 0 & - & - \\
\hline $1.0 \mathrm{~m}$ & 29 & 20 & 70 & 0 & - & - \\
\hline $1.5 \mathrm{~m}$ & 29 & 20 & 80 & 0 & - & - \\
\hline Freezing & $12-48 \mathrm{~h}$ & 16 & 63 & 0 & - & - \\
\hline
\end{tabular}

experiments with packets stored at $20-25^{\circ} \mathrm{C}$ in which amphipods were exposed on a weekly basis demonstrated that oncospheres stored at these temperatures survive for 2 weeks.

Survivorship of the Hyalella and the infection levels observed in each experiment are summarized in Table 1. Regression analysis revealed that the mean percentage of amphipods surviving was similar in all groups in experiment $1\left(F_{[1,6]}=\right.$ $3.19 ; P>0.1)$. The percentage of the survivors that were infected, however, declined significantly with increasing age of the oncospheres $\left(Y=106.98-2.92 X ; F_{[1,6]}=36.87 ; P<\right.$ $\left.0.001 ; r^{2}=0.84\right)$. Similarly, the mean intensity of cysticercoids declined significantly with increased age of the oncospheres $\left(Y=5.63-0.13 X ; F_{[1,247]}=115.3 ; P<0.001\right.$; $\left.r^{2}=0.32\right)$.

Although fewer amphipods exposed to egg packets stored at $20^{\circ} \mathrm{C}$ for 28 days survived than those exposed to fresh packets (controls) the difference was not significant $\left(\chi^{2}=2.29 ; 1 \mathrm{df}\right.$; $P>0.05)$. Significantly fewer ( 2 of $38 ; 5.3 \%)$ of the surviving amphipods were infected $\left(\chi^{2}=69.19 ; 1 \mathrm{df} ; P<0.001\right)$. These harboured one and four cysticercoids.

None of the amphipods exposed to overwintered or frozen oncospheres became infected.

There was no relationship between host size and the intensity of infection $\left(F_{[1,229]}=0.08 ; P=0.78\right)$. The mean head length of uninfected $(0.51 \pm 0.18 \mathrm{~mm} ; n=20)$ and infected $(0.49 \pm 0.07 \mathrm{~mm} ; n=145)$ amphipods exposed to control, 4-, 8-, and 12-week-old oncospheres (i.e., those intervals during which the prevalence of infection among the survivors was $>80 \%$ ) did not differ significantly (ANOVA; $F_{[1,163]}=1.7$; $P=0.19$ ).

\section{Discussion}

None of the oncospheres that had been frozen produced infections in the amphipods. Oncospheres of Drepanidotaenia lanceolata and Diorchis stefanskii are also killed by freezing (Kisilewska 1957; Baginska-Olszewska and Grytner-Ziecina 1978); on the other hand, 20-35\% of Sobolevicanthus gracilis oncospheres survived freezing for up to $24 \mathrm{~h}$ and $2 \%$ survived freezing for 5 weeks (Grytner-Ziecina 1980). However, the evidence indicates that few, if any, hymenolepidid oncospheres deposited in locations shallow enough to freeze to the bottom survive to contribute to the infective pool.

Initial studies indicated that oncospheres stored at low temperatures $\left(5\right.$ and $\left.10^{\circ} \mathrm{C}\right)$ could survive for at least 20 weeks. Those stored at $15^{\circ} \mathrm{C}$ survived for shorter periods. However, data from related studies of the same duration, but in which the effects of different $\mathrm{pH}$ were evaluated, indicate that survival of oncospheres stored at $15^{\circ} \mathrm{C}$ at $\mathrm{pH} 6$ is comparable to that at 5 or $10^{\circ} \mathrm{C}$ for up to 20 weeks (Pilgrim 1990). These results indicate that oncospheres of Microsomacanthus hopkinsi can survive equally well over a range of cooler temperatures $\left(5-10^{\circ} \mathrm{C}\right)$ for at least 20 weeks. This needs further study, but we speculate that survival of the oncospheres does not differ significantly over a range of lower temperatures.

As expected, infection levels declined over time, but some oncospheres in nearly half of the packets stored for 24 weeks at $7{ }^{\circ} \mathrm{C}$ were still infective. However, only two amphipods exposed to oncospheres stored for 28 weeks became infected and none of the packets that had overwintered in the lake produced infections. These were slightly older ( 29 weeks) than the oldest oncospheres stored at $7^{\circ} \mathrm{C}$ and had been in colder water for much of that time. As oncospheres appear to survive for comparable periods over a range of lower temperatures, it seems unlikely that the slightly cooler conditions would prolong survivorship significantly. These results suggest that 28-29 weeks approaches the maximum survival time for oncospheres of $\boldsymbol{M}$. hopkinsi. However, mortality increases rapidly beyond 24 weeks and few oncospheres survive this long.

Hyalella azteca is the only known intermediate host of M. hopkinsi (McLaughlin and Burt 1970; Podesta and Holmes 1970). While several cohorts are produced each summer, only the last overwinters (de March 1981). Hyalella becomes inactive below $10^{\circ} \mathrm{C}$ and does not feed (de March 1981). Oncospheres not eaten in the fall are, therefore, unlikely to be eaten before water temperatures rise above $10^{\circ} \mathrm{C}$ in spring. The length of the inactive period is critical because the oncospheres must survive this period if they are to contribute to the infective pool in the spring. This suggests that there is a northern limit 
beyond which the inactive period of the amphipod host is too long for the oncospheres to bridge. Assuming an absence of other mortality factors, our results indicate that about $40 \%$ of the packets deposited on November 1, for example, would contain viable oncospheres on April 15 (24 weeks). If the amphipod populations were active by then, viable oncospheres would also be available. In more southerly areas where the inactive period is shorter, overwintering oncospheres are a potentially important source of the cysticercoid pool in amphipod populations. This might account, in part, for the fact that $M$. hopkinsi is one of the more common cestodes found in ducks returning in the spring (Buscher 1965; McLaughlin and Burt 1979).

Oncospheres of $M$. hopkinsi are capable of surviving in reasonable numbers at low temperatures for significantly longer periods than those of $D$. lanceolata, $D$. stefanskii, or $S$. gracilis. These survive a maximum of 25,80 , and 140 days at comparable temperatures (Kisilewska 1957; Baginska-Olszewska and Grytner-Ziecina 1978; Grytner-Ziecina 1980). Survival time of oncospheres at lower temperatures clearly varies widely among species and it does not appear that those of the latter three species have the potential to survive the winter under Canadian conditions.

Whether cysticercoids present in $H$. azteca populations in the spring represent overwintered infections or more recent infections acquired from overwintered eggs, they are only available to ducks for a short time because the cohort dies following the production of one, or a few, broods (de March 1981). The overwintering question aside, the ability of the oncospheres to survive for extended periods at low temperatures ensures that foci established by ducks returning in the spring persist until members of the new amphipod cohort are large enough to support infections.

Oncospheres survive for increasingly shorter periods as water temperatures rise (Grytner-Ziecina 1980). Survival times for oncospheres of $M$. hopkinsi stored at 20 and $25^{\circ} \mathrm{C}$ were similar to each other and to those of other hymenolepidids at similar temperatures. Oncospheres of D. lanceolata (Kisilewska 1957), D. stefanskii (Baginska-Olszewska and Grytner-Ziecina 1978), S. gracilis (Grytner-Ziecina 1980), Microsomacanthus paramicrosoma, and Microsomacanthus paracompressa (Egizbaeva and Akaev 1973), and some unidentified hymenolepidids (Petrov 1973) survive for $21,23,35,16$, and 30 days, respectively, in temperatures ranging from 16 to $24^{\circ} \mathrm{C}$. Foci established in warmer conditions persist for shorter periods, and as the survival times reported are maxima, the effective duration of foci under these conditions may be considerably less. Our results suggest that foci of $M$. hopkinsi would only last for about 2 weeks where water temperatures reach or exceed $20^{\circ} \mathrm{C}$.

Usually, only a small percentage of the population of a particular duck or goose species returning in the spring is infected with a given hymenolepidid species (Buscher 1965; McLauglin and Burt 1979; Neraasen and Holmes 1975). If these helminth populations were the only source of infective material, the diversity in the local infective pools, at least in spring and early summer, would be limited to species introduced that year.

Within limitations, overwintered stages may contribute to the helminth populations in ducks arriving in spring. Overwintered stages, therefore, may influence the size and diversity of local infective pools. Overwintered oncospheres of $M$. hopkinsi are potential contributors to the infective pools in amphipods on the breeding grounds, provided that the inactive period of the amphipod host does not exceed 24 weeks. However, the evidence available suggests that neither they, nor the oncospheres of other hymenolepidid species studied, survive long enough to contribute to infective pools in more northerly areas. Overwintering oncospheres may be of greater significance along migration corridors where sites are used later in the fall and earlier in the spring by migrant waterfowl.

\section{Acknowledgements}

We thank the Canadian Wildlife Service for the necessary permits (W. Pilgrim and J. D. McLaughlin) to collect the duck hosts. Dr. George Hochbaum, Canadian Wildlife Service, Winnipeg, generously permitted fecal collections from ducklings caught in his banding work in the Delta Marsh. The work was supported by the General Research Fund, Concordia University (J. D. McLaughlin) and by Natural Sciences and Engineering Research Council of Canada grant No. 2358 (M. D. B. Burt). Judy and Peter Blundell, Lakefield, Quebec, graciously provided access to the lake where the overwintering experiments were conducted and their cooperation is deeply appreciated. Irene Menaggia kindly translated Kotel'nikov's paper from Russian. Dr. N. N. Kapoor, Concordia University, assisted with the photography.

Baginska-Oslezska, G., and Grytner-Ziecina, B. 1978. The effect of temperature and time on the infective larvae of the oncospheres of Diorchis stefanskii Czaplinski, 1956 and Sobolevicanthus gracilis (Zeder, 1803). In Proceedings of the 4th International Congress of Parasitology, Section A, 13, Warsaw, Poland, August 19-26, 1978. Edited by The Committee for Parasitology of the Polish Academy of Sciences. Polish Scientific Publishers, Warsaw.

Birova, V., Macko, J. K., and Spakulova, M. 1989. Seasonal dynamics of the invasion cycle of platyhelminths in the wild (Anas platyrhynchos L.) and domestic duck (Anas platyrhynchos $\mathrm{f}$. dom.). II. Cestoda. Helminthologia, 26: 147-154.

Buscher, H. N. 1965. Dynamics of the intestinal helminth fauna in three species of ducks. J. Wildl. Manage. 29: 772-781.

Czaplinski, B., and Szelenbaum, D. 1974. The ability of larvae of Hymenolepididae to survive the winter within Ostracoda under natural conditions. In Proceedings of the 3rd International Congress of Parasitology, Munich, Federal Republic of Germany, August 25-31, 1974. Facta Publications, Vienna. pp. 385-386.

de March, B. G. E. 1978. Effects of constant and variable temperatures on the size, growth, and reproduction of the freshwater amphipod Hyalella azteca (Saussure). Can. J. Zool. 56: 1801-1806.

de March, B. G. E. 1981. Hyalella azteca (Saussure). In Manual for the culture of selected freshwater invertebrates. Edited by S. G. Lawrence. Can. J. Fish. Aquat. Sci. Spec. Publ. No. 54. pp. $61-77$.

Egizbaeva, Kh. I., and Akaev, A. 1973. Some aspects of the biology and epizootology of Microsomacanthus in ducks (M. paramicrosoma, $M$. paracompressa). (In Russian.) In Zhiznennye tsikly gel'mintov zhivotnykh Kazakhstana. (Sbornik). Institut Zoologii, Akademiya Nauk Kazakhskoi SSR, Alma - Ata. pp. 96-100.

Grytner-Ziecina, B. 1980. The influence of temperature, time and the seasons of the year on the infective activity of Sobolevicanthus gracilis (Zeder, 1803) larvae. Acta Parasitol. Pol. 27: 451-457.

Kisilewska, K. 1957. Influence of some factors on the survival and invasity [sic] of eggs of the tapeworm Drepanidotaenia lanceolata (Bloch) and the further development of larvae from such eggs. Acta Parasitol. Pol. 5: 585-598.

Kornyushin, V. V. 1973. The dependence of the cestode fauna of birds on the seasonal changes in bird life. (In Ukrainian.) In Paraziti, parazitozi ta shlyakhi ikh likvidatsii (Parazity, parazitozy i puti ikh likvidatsii). No. 2. Naukova Dumka. Kiev, USSR. pp. 32-38.

Kotel'nikov, G. A. 1969. Survival of larvae of bird helminths in water reservoirs during autumn, winter and spring. (In Russian.) 
Sbornik Trudov. Vsesoyuznyi Nauchno-issledovatel'skii Institut po Boleznyam Ptits. 3: 234-243.

McLaughlin, J. D., and Burt, M. D. B. 1970. Observations of the morphology and life cycle of Hymenolepis hopkinsi, a parasite of black ducks (Anas rubripes). Can. J. Zool. 48: 1043-1046.

McLaughlin, J. D., and Burt, M. D. B. 1973. Changes in the cestode fauna of the black duck Anas rubripes (Brewster). Can. J. Zool. 51: $1001-1006$.

McLaughlin, J. D., and Burt, M. D. B. 1979. A survey of the intestinal helminths of waterfowl from New Brunswick, Canada. Can. J. Zool. 57: 801-807.

Mineev, V. V. 1980. The infectivity of larvae of bird helminths. Veterinariya (Moscow), 10: 42.

Nerassen, T. G., and Holmes, J. C. 1975. The circulation of cestodes among three species of geese nesting on the Anderson River Delta, Canada. Acta Parasitol. Pol. 23: 277-289.

Petrov, Yu.F. 1973. The survival of the ova of some helminths of aquatic birds in the water bodies of northern and central Kazakhstan. (In Russian.) Sbornik Nauchno-Issledovatel'skii po Boleznyam Ptits. 9: $231-234$.

Pilgrim, W. 1990. The effect of $\mathrm{pH}$ and temperature on the anseriforme cestode Hymenolepis hopkinsi and its intermediate host the fresh water amphipod Hyalella azteca. M.Sc. thesis, Department of Biology, University of New Brunswick, Fredericton, N.B.

Podesta, R. B., and Holmes, J. C. 1970. Hymenolepid cysticercoids in Hyalella azteca of Cooking Lake, Alberta: life cycles and descriptions of four new species. J. Parasitol. 56: 1124-1134.

Rysavy, B. 1961. The problem of resevoir parasitism in hymenolepididae. Helminthologia, 3: 288-293.

Schiller, E. L. 1954. Studies on the helminth fauna of Alaska. XVIII. Cestode parasites in young anseriformes on the Yukon Delta nesting gounds. Trans. Am. Microsc. Soc. 73: 194-201.

Spakulova, M., Macko, J. K., and Birova, V. 1989. Seasonal changes in the species diversity of the duck platyhelminths in East Slovakia. Helminthologia, 26: 195-209.

Tsimbalyuk, A. K. 1965. Helminth fauna of Anas platyrhynchos nesting and wintering on the Kommandor Islands. (In Russian.) Vestnik Leningradskogo Universiteta. Ser. Biol. 20: 160-164.

Wallace, B. M., and Pence, D. B. 1986. Population dynamics of the helminth community from migrating blue-winged teal: loss of helminths without replacement on the wintering grounds. Can. J. Zool. 64: 1765-1773. 